\title{
ASI Elections! Stop the SMS Campaign!!
}

\author{
Gabriel Rodrigues
}

Received: 5 August 2010 /Accepted: 20 September 2010 /Published online: 11 October 2011

(C) Association of Surgeons of India 2011

\section{Dear Editor,}

Association of Surgeons' of India (ASI) elections have definitely become a 'fierce battle' being fought since few years. Canvassing for various posts by the candidates through information leaflets/letters by surface mail, e-mails and SMS has become rampant. Canvassing is a healthy practice so that the members of ASI electorate know their candidates well, as it is the 'need of the hour' to have able administrators at the helm of affairs for the betterment of our own association. While information by post and e-mail is welcome, the 'SMS campaign' and personal calls can be extremely irritating!

And now again, there seems to be an election for the President Elect 2013 and other posts of ASI, and this reminds me of those irritating SMS that are sent by all the contesting candidates irrespective of the time of the day! It's no short of a nightmare! Why I say this is that, last couple of times it has become a craze for all the candidates to send SMS and it is really irritating! Being a professor in a medical college hospital, I have been in a bedside clinic teaching medical students or in a general clinic of PG's or seeing patients in OPD or in the OT and then there is an SMS! Can you imagine how one feels... This is again in addition to the detailed CVs of all the contestants mailed to ASI members from the central office and individual candidates sending personal letters as well. Then what is the point in sending those irritating SMS again and again? Contestants should realize that this will not help, as members would have already made up their minds as to whom to vote for! The more the SMS, the less is the chance of that candidate winning. Hence, I would like to request the present office bearers of ASI to please instruct the contestants to REFRAIN from SMS campaign and personal calls and give some peace of mind to all the ASI members. I would like the probable contestants to note the same and spare us!!

Conflict of interest Nil

Sources of funding Nil

G. Rodrigues $(\bowtie)$

Department of General Surgery, Kasturba Medical College,

Manipal University,

Manipal, 576104, Karnataka, India

e-mail: gabyrodricks@gmail.com 